\title{
Research on Bending Bearing Capacity of Simply Supported Reactive Powder Concrete Beams
}

\author{
Kai Yan ${ }^{1, \text { a }}$, Chunnuan $\mathrm{Luo}^{1}$, YaoYao Niu ${ }^{1}$ and Cheng $\mathrm{Xu}^{1}$ \\ ${ }^{1}$ School of Civil Engineering, Shandong Jianzhu University, Jinan 250101, China. \\ a yankai@sdjzu.edu.cn
}

Keywords: Reactive powder concrete; Simply supported beam; Static test; Ultimate bending moment; Cracks.

\begin{abstract}
Super-high compressive strength, high tensile strength (12 25MPa) and excellent ductility of steel fiber-reinforced reactive powder concrete (SRPC) cause significant difference on structural failure between SRPC structures and ordinary concrete structures. The behavior of SRPC continuous beams is investigated experimentally and numerically in this paper. Five tests were conducted by the authors to obtain the crack distribution and growth, the stain in steel bar during the ultimate load test. The load-deflection behavior and modes of failure are presented for the five tests. A nonlinear finite element model, exploiting the SRPC damaged plasticity material model, was developed and verified against the tests. A parametric study was conducted to study the effects on the global structural behavior due to the change in the SRPC continuous beams geometry, load form, SRPC strength and boundary conditions. The experimental and numerical results were compared with values calculated using current design codes. It is shown that the ultimate loads calculated using current codes are conservative for the SRPC continuous beams investigated in this study. The formulations of the length of equivalent plastic hinge zone and the method of bending moment amplitude modulation are proposed for SRPC continuous beams. The results presented in this paper provide a valuable insight into the behavior of SRPC continuous beams, and can be used as basic reference for structure design of SRPC engineering structures.
\end{abstract}

\section{Introduction}

Reactive powder concrete (RPC for short) was a kind of cement base composite materials which has several excellent properties, such as ultra-high strength, toughness, and durability[1]. At present, the materials, mixing ratio, maintenance, durability and strength of a large amount of RPC has been experimented. Xie[2] carried out RPC material test by incorporating the superfine fly ash, adopting the wet and heat curing method formulated the reactive powder concrete with the compressive strength of 200MPa. Roux[3] studied on the durability of RPC, found its durability was 70 times of the ordinary C30 concrete. Zheng[4] preliminarily proposed the calculation method of mixture ratio of reactive powder concrete. It also has been applied in number of projects, such as coastal engineering, nuclear power plant, etc [5-6]. Wan[7] established calculation model of the anti-cracking of the normal section of reactive powder concrete beam and put forward the calculation formula of anti-cracking of normal section, the plastic influence coefficient of sectional resistance moment were set as 1.65 (for rectangular section) and 1.9 (for T section). Wang[8] based on the stress experiment of 3 reinforced RPC beams, put forward the calculation formula of the bearing capacity of the normal section of reinforced RPC beam, the stress figure of the section in the compression zone referring to the methods for ordinary concrete was modeled as rectangular stress figure calculation, the resultant tensile stress of reactive powder concrete in the tensile zone was obtained inversely through the test result.

In this paper, 6 reinforced reactive powder concrete beams were tested according static testing rules, the compressive strain and the strain distribution along the height of the beam at the edge in the compressive zone in the pure bending section of each type of beam under various levels of load was 
obtained, and the cracking moment and ultimate bending moment of the test beam was obtained, the deformation and fracture distribution and development of the experimental beams was examined.

\section{Experimental Details}

Reinforcement ratio was the main factor affecting the bearing capacity, stiffness and crack distribution and propagation of beams. According to the material property of test RPC and rebar and the cross section of specimen, the minimum reinforcement ratio was obtained as $0.31 \%$, the critical reinforcement ratio as $10.00 \%$. In the test, one low-reinforced beam and one balanced reinforcement beam were prepared to study the difference with the common reinforced concrete beam. The reinforcement ratio for the rest four common reinforced concrete beams was between $0.31 \%$ and $10.00 \%$. Each specimen was $1800 \mathrm{~mm}$ long, to prevent the anchor damage, $300 \mathrm{~mm}$ shall be set aside on each side of the support, so the span was $1200 \mathrm{~mm}$, the size of cross section was $150 \mathrm{~mm} \times 200 \mathrm{~mm}$. the rebar of beam was shown in Fig. 1.

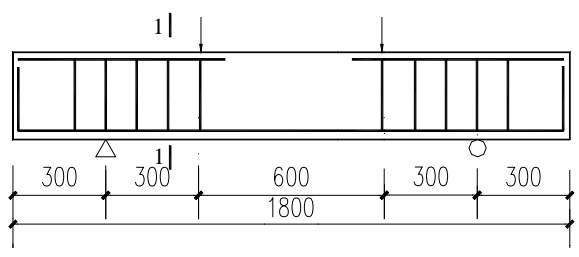

Fig.1 Reinforced RPC beams

Table 1 Parameters of Specimens

\begin{tabular}{|c|c|c|c|c|c|c|c|}
\hline $\begin{array}{l}\text { Specimen } \\
\text { No. }\end{array}$ & $\begin{array}{l}\text { Longitudinal } \\
\text { rebar }\end{array}$ & Bearing rod & $\begin{array}{c}\text { Reinforcement } \\
(\%)\end{array}$ & Stirrup & $\underset{2}{\mathrm{~A}_{\mathrm{s1}} / \mathrm{mm}}$ & $\mathrm{A}_{\mathrm{s} 2} / \mathrm{mm}^{2}$ & $\mathrm{~S}_{1} / \mathrm{mm}$ \\
\hline L-1 & $2 \phi 6$ & $2 \phi 6$ & 0.23 & ф 6@150 & 28 & - & - \\
\hline L-2 & $2 \Perp 14$ & $2 \phi 6$ & 1.50 & ф 10@80 & 32 & - & - \\
\hline L-3 & $2 \Perp 22$ & $2 \phi 6$ & 3.07 & ф 10@80 & 36 & - & - \\
\hline L-4 & $3 \| 18$ & $2 \phi 6$ & 3.08 & ф10@80 & 34 & - & - \\
\hline L-5 & $2 \Perp 25+1 \Perp 22$ & $2 \phi 6$ & 5.90 & 112@60 & 37.5 & 68.3 & 25 \\
\hline L-6 & $2 \Perp 22+1 \Perp 40$ & $2 \phi 6$ & 10.00 & 112@60 & 30 & 81 & 40 \\
\hline
\end{tabular}

\section{Experimental Result}

The failure mode of all of the specimens is bending failure. L-1 experienced under-reinforced damaged, specimen was damaged after the RPC in the tensile zone failed. When the specimen was damaged, rebar in the pure bending section yields, compressive zone of RPC was not crushed, deflection was $26.6 \mathrm{~mm}$. The crack width was up to $10 \mathrm{~mm}$. L-6 was characterized by over-reinforced damage, the rebar in pure bending section did not yield, compressive zone of RPC was crushed suddenly. The propagation of crack in the tensile zone was not wide and distribution was relatively close. The damaged deflection was $9.4 \mathrm{~mm}$. The rest four specimens experienced optimum reinforcement damage. The longitudinal steel of pure bending section yielded first, and then the RPC in the compressive zone was crushed. The measured value of ultimate compressive strain at the edge in the compression zone of RPC of the specimen in the pure bending section was $5500 \times 10^{-6}$, and the measured value of cracking strain at the edge in the compression zone of RPC of the specimen in the pure bending section was $750 \times 10^{-6}$. 
Table 2 Cracking moment $M_{\mathrm{t}, \mathrm{cr}}$ and ultimate moment $M_{\mathrm{t}, \mathrm{u}}$ of specimens

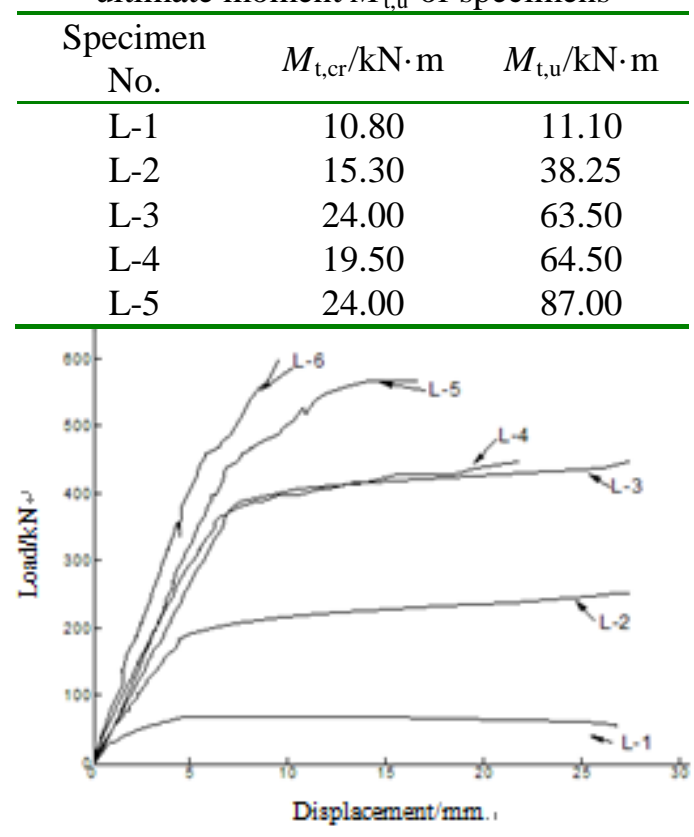

Fig. 2 Load-displacement curves of specimens

The cracking moment $M_{\mathrm{t}}$, ultimate bending moment $M_{\mathrm{t}, \mathrm{u}}$ of each specimen were shown in table 2 . The average crack width and the average crack spacing under the action of $40 \% \sim 65 \%$. The value noted near the crack was the concentrated load imposed in the propagation process by jacks, with the unit as kN. Fig. 2 shows the load- displacement curves of 6 specimens, with $y$-axis as the concentrated load imposed by jack.

\section{Test Result Analysis}

According to the principle of size of stress and point of action will not change, stress-strain curve of RPC in compression and tension and the measured ultimate compressive strain on the edge in compressive zone of specimens, the stress figure of the compressive zone of the normal section of RPC beam was modeled as rectangular stress figure, to facilitate the calculation of flexural bearing capacity. Figure 6 was the stress distribution of the section of optimum reinforced RPC beam under the action of ultimate load and the equivalent stress distribution.

$M_{\mathrm{u}}$ was the ultimate bending moment of RPC beams, and $\alpha$ was the equivalent rectangular stress figure coefficient for compressive zone. According to the stress-strain relations and the cross-section equilibrium conditions of RPC, based on the principle of size of stress and point action will not change, $\alpha=0.9, \beta=x / x_{0}=0.77 . x_{0}$ was the height of actual compression zone. The equivalent stress in the compressive zone of RPC was $\alpha f_{\mathrm{c}}$. The height of actual compression zone was $x . x_{\mathrm{t}}$ was the height of tensile zone. The equivalent stress in the tensile zone of RPC was $\alpha f_{t}$. $k$ was the equivalent coefficient. It needs to be pointed out that because of the uneven distribution of compressive strain in the compressive zone, there was strain gradient of compressive strain, and theoretically, it should not be less than 1. In the TJ10-74 Reinforced Concrete Structure Design Code, $\alpha=1.25$. in GBJ10-89 Code For Design Of Concrete Structures, $\alpha=1.1$. Due to the development of economy, in GB50010-2002 code for design of concrete structures, $\alpha$ was determined to be 1.0. As to this paper, the intrinsic nature of reason for choosing $\alpha$ of the RPC beam to be 0.9 will be continually explored. 


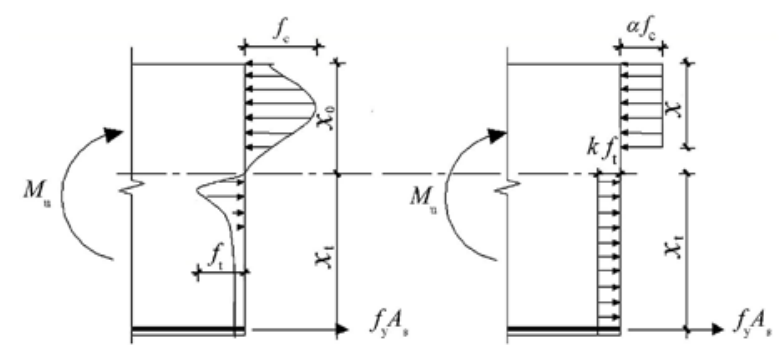

a)Actual stress distribution b)Equivalent stress distribution

Fig. 3 Stress distribution of reinforcement beam
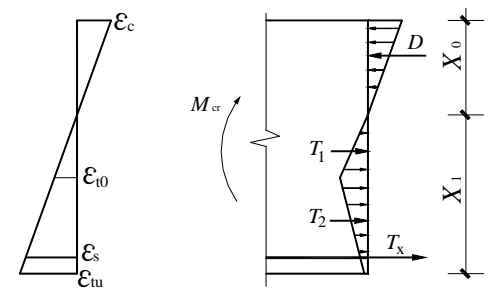

(a) strain distribution (b) stress distribution Fig. 4 Stress and strain distribution of the section

To simplify the calculation, equivalent rectangular stress was used in Fig. 3b to mode the resistance of the actual tensile stress distribution of the curve figure $6 \mathrm{a}$. The equivalent coefficient can be calculated based on the equilibrium conditions and the test result. As shown in Fig. 3, according to the balance of force and balance of moment of force, formula (1) and formula (2) can be obtained. In the formula: $b$ was the cross section width of the specimen, $h$ was the height of cross section, $a_{\mathrm{s}}$ was the distance from the center of steel under tension to the edge under tension of the section. $h_{0}$ was the effective height of the section. The meanings of the rest symbols are as following.

Table 3 Test result, calculated value of bearing capacity of

RPC beams, and equivalent coefficient $k$ in tensile zone

\begin{tabular}{cccccc}
\hline Specimen. & $\begin{array}{c}M_{\mathrm{c}, \mathrm{u}} / \mathrm{kN} \cdot \\
\mathrm{m}\end{array}$ & $\begin{array}{c}M_{\mathrm{t}, \mathrm{u}} / \mathrm{kN} \cdot \\
\mathrm{m}\end{array}$ & $\begin{array}{c}M_{\mathrm{cr}} / \mathrm{kN} \cdot \\
\mathrm{m}\end{array}$ & $M_{\mathrm{c}, \mathrm{u}} / M_{\mathrm{t}, \mathrm{u}}$ & $k$ \\
\hline L-1 & 11.94 & 10.80 & 11.94 & 1.11 & - \\
L-2 & 29.95 & 38.25 & 15.99 & 0.78 & 0.44 \\
L-3 & 57.49 & 63.00 & 22.10 & 0.91 & 0.28 \\
L-4 & 58.48 & 64.50 & 22.14 & 0.91 & 0.27 \\
L-5 & 85.97 & 87.00 & 23.76 & 0.99 & 0.31 \\
\hline
\end{tabular}

$\left\{\begin{array}{l}\alpha f_{\mathrm{c}} b x=f_{\mathrm{y}} A_{\mathrm{s}}+k f_{\mathrm{t}} b\left(h-\frac{x}{\beta}\right) \\ M_{\mathrm{u}}=\alpha f_{\mathrm{c}} b x\left(h_{0}-\frac{x}{2}\right)-k f_{\mathrm{t}} b\left(h-\frac{x}{\beta}\right)\left[0.5\left(h-\frac{x}{\beta}\right)-a_{\mathrm{s}}\right]\end{array}\right.$

(1)

Combining formula (1) and (2), and multiplying the measured ultimate bending moment $M_{\mathrm{t}, \mathrm{u}}$, the equivalent coefficient $k$ can be obtained, as shown in table 3 .

Integrating the calculation result of four specimens, it was better to choose $k=0.25$ for safety. For under reinforced beam, due to the crack width of ultimate load was relatively large, therefore the role of the tensile zone of RPC does not need be considered, the calculation method of its bearing capacity was the same with the ordinary concrete rebar under reinforced beam. Although the crack width of the over-reinforced beam damage was not big, but because the RPC has high tensile strength, when calculating the bearing capacity, the function of RPC in the tensile zone still need be considered, approximately $k=0.25$, the calculation shall be conducted according to the formula (3).

$$
M_{\mathrm{u}, \max }=\alpha f_{\mathrm{c}} b h_{0}^{2} \xi_{\mathrm{b}}\left(1-0.5 \xi_{\mathrm{b}}\right)-k f_{\mathrm{t}}\left(h-\frac{x}{\beta}\right)\left[\frac{1}{2}\left(h-\frac{x}{\beta}\right)-a_{\mathrm{s}}\right]
$$

In the formula, $M_{\mathrm{u}, \max }$ is ultimate bearing capacity of RPC over-reinforced beam, and $\xi_{\mathrm{b}}$ was the height of relative boundary compressive zone.

The calculated value of the bending bearing capacity of 6 specimens were obtained according to the formula (3), (4) and (5), and the result were compared with the test result $M_{\mathrm{t}, \mathrm{u}}$. the mean of $M_{\mathrm{c}, \mathrm{u}} / M_{\mathrm{t}, \mathrm{u}}$ was 0.95 , the mean square deviation was $\sigma=0.010$, coefficient of variation was . It can be seen the result was safe. Specific result was shown in table 3.

Under the cracking load, the compressive stress at the edge in the compressive zone of the RPC was relatively small, and was at the elastic phase, with the stress distribution approximately in the shape of triangle. The stress distribution of RPC in the tensile zone was in the curved shape. In order 
to simplify the calculation, it was approximated as triangular and trapezoidal distribution. According to the compressive strain and tensile stress balance condition of RPC at the edge in the compression zone under the cracking load of each specimen, the tensile stress of RPC at the edge in the compression zone was determined as $0.1 f_{\mathrm{t}}$. Stress and strain distributions are shown in Fig. 4.

According to the stress-strain relationship curves of RPC, the ratio of the strain $\varepsilon_{\mathrm{t} 0}$ corresponding to the peak tensile stress in the tensile zone of RPC $\varepsilon_{\mathrm{t} 0}\left(\varepsilon_{\mathrm{t} 0}=249 \times 10^{-6}\right)$ to the measured value $\varepsilon_{\mathrm{tu}}$ $\left(\varepsilon_{\mathrm{tu}}=750 \times 10^{-6}\right)$ of the cracking strain at the edge in the tensile zone of RPC in the pure bending section of the test beam was:

The height of compressive zone:

$$
\frac{\varepsilon_{\mathrm{t} 0}}{\varepsilon_{\mathrm{tu}}}=\frac{249}{750}=\frac{1}{3.03}=0.33
$$

$$
x_{0}=\left(-\left(10.873 b h+3.03 E_{s} A_{s} \varepsilon_{\varepsilon_{0}}\right)+\sqrt{\left.\frac{\left(10.873 b h+3.03 E_{s} A_{s} \varepsilon_{0}\right)^{2}+4\left(1.515 E_{E} b \varepsilon_{10}-5.43 b\right)\left(5.43 b h^{2}+3.03 E_{s} A_{3} \varepsilon_{10} h_{0}\right)}{2\left(1.515 E_{c} b \varepsilon_{10}-5.43 b\right)}\right)}\right.
$$

According to moment balance of section:

$$
\begin{aligned}
& M_{\mathrm{c}}=1.515 \times \frac{2}{3} \times E_{\mathrm{c}} b \frac{x_{0}^{3}}{h-x_{0}} \varepsilon_{010}+2.524 b\left(h-x_{0}\right)^{2}+3.03 E_{\mathrm{s}} A \varepsilon_{\mathrm{s}} \frac{\left(h_{0}-x_{0}\right)^{2}}{h-x_{0}}=f_{\mathrm{t}} W_{\mathrm{s}} \\
& W_{s}=\left[1.01 E_{c} b \frac{x_{0}^{3}}{h-x_{0}} \varepsilon_{10}+2.524 b\left(h-x_{0}\right)^{2}+3.03 E_{s} A \varepsilon_{s} \frac{\left(h_{0}-x_{0}\right)^{2}}{h-x_{0}}\right] / f_{t}
\end{aligned}
$$

Cracking bending moment can be calculated by formula (9).

$$
M_{\mathrm{cr}}=\gamma_{\mathrm{m}} f_{\mathrm{t}} W_{0}
$$

Where: $\gamma_{\mathrm{m}}$ was the plasticity coefficient of the section; $W_{0}$ was the elastic resistance moment of the section translating the rebar to reactive powder concrete to the edge in the tensile zone of the section. Longitudinal rebar in the tensile zone was converted to be the area of the RPC, and the ratio of rebar to elastic modulus of RPC was:

$$
\alpha_{\mathrm{Er}}=E_{\mathrm{s}} / E_{\mathrm{rc}}=200000 / 41237=4.85
$$

The distance from the geometric centroid of Cross section to the edge of the compressive zone was:

$$
x_{1}=\frac{\frac{1}{2} b h^{2}+\left(\alpha_{\mathrm{Er}}-1\right) A_{s} h_{0}}{b h+\left(\alpha_{\mathrm{Er}}-1\right) A_{\mathrm{s}}}
$$

The moment of inertia of the section to the centroid was converted as follows:

$$
W_{0}=\frac{I_{\mathrm{y}}}{h-x_{1}}=\frac{b h^{3}+3 b h\left(2 x_{1}-h\right)^{2}+12 \mathrm{~A}_{3}\left(\alpha_{\mathrm{Er}}-1\right)\left(h_{0}-x_{1}\right)^{2}}{12\left(h-x_{1}\right)}
$$

Combining formula (7) and (9), then:

$$
\gamma_{\mathrm{m}}=W_{\mathrm{s}} / W_{0}
$$

Taken its lower envelope (due to the limited number of specimens, the turning point of envelope was taken as $4.3 \%$ temporarily), the volume content of steel fiber (flat steel fiber with diameter of 0.22 $\mathrm{mm}$, and length to diameter ratio as 59.1 ) was obtained as $2 \%$ by means of fitting. The calculation formula of the RPC rectangular section beam (section height as $200 \mathrm{~mm}$ ) with the compressive strength of prism as about $100 \mathrm{MPa}$ is:

$$
\gamma_{\mathrm{m}}= \begin{cases}1.1+18.4 \rho & \rho<4.3 \\ 1.89 & \rho \geq 4.3\end{cases}
$$

In the formula, $\rho$ is the reinforcement ratio of longitudinal steel bar. The calculated values of the cracking moment of 6 specimens are shown in Table 3.

\section{Conclusion}

(1) The test result show that the ultimate compressive strain at the edge in the compressive zone of RPC test beam was $5500 \times 10^{-6}$. The cracking strain of pure bending section was $750 \times 10^{-6}$. The calculation of plasticity coefficient of section should consider the beneficial effects of longitudinal tensile rebar, thus the calculation formula of the plasticity coefficient of sectional resistance moment was put forward. 
(2) The calculation formula of the bearing capacity of the normal section considering the contribution of the tensile stress in the tensile zone and the calculation methods of the stiffness and crack width of the reinforced reactive powder concrete beam reflecting its mechanical characteristics were established.

\section{Acknowledgments}

This study was financed by the Program for Changjiang Scholars and Innovative Research Team in University of China (grant no. IRT13075), and the National Natural Science Foundation of China (grant no. 51408341 and 51478254).

\section{References}

[1] R. Pierre. Reactive powder concrete: a new ultra-high strength cementations material. The 4th International Symposium on Utilization of High Strength/Hugh Performance Concrete. Paris, France. Presses des Ponts et Chaussees, 1996:1343-1349.

[2] Y. J. Xie, B. J. Liu, G. C. Long. Study on reactive powder concrete with ultra-pulverized fly ash. Journal of Building Materials, 4(2001)280-284.

[3] B. N. Roux, C. Andradej, M. A. Sanjuan. Experimental study of durabilty of reactive powder concretes. Journal of Materials in Civil Engineering. 8 (1996)1-6.

[4] W. Z. Zheng, L. Li. Preparation and mix proportion calculation of reactive powder concrete. Journal of Hunan University: Natural Sciences. 36 (2009) 13-17.

[5] Y. Zhang. Application and development of reactive powder concrete in structure engineering. Henan building materials. 4 (2003) 13-20.

[6] W. Y. Zhou. Application of reactive powder concrete in bridge and road engineering. Port and Waterway Engineering. 12 (2004) 103-105.

[7] J. M. Wan, R. Gao. Calculating method of crack-resistant capacity of reactive powder concrete beam. Building Structure. 12 (2007) 93-96.

[8] Z. N. Wang. Research on flexural behavior of reactive powder concrete rectangular beam with steel bars. Beijing Jiaotong University, 2008. 